\title{
CERTAIN OLFACTORY CENTERS OF THE FOREBRAIN OF THE GIANT PANDA (AILUROPODA MELANOLEUCA)
}

\author{
EDWARD W. LAUER \\ Department of Anatomy, Vniversity of Michigan ${ }^{3}$ \\ THIRTEEN FIGURES \\ INTRODUCTION
}

In the spring of 1946 the Laboratory of Comparative Neurology at the University of Michigan received from Professor Fred A. Mettler of Columbia University the brain of a giant panda (Ailuropoda melanoleuca) for histological study. This had been obtained from a mature female melanoleuca, Pan Dee, presented to the New York Zoological Society in 1941 through United China Relief by Mme. Chiang Kai-shek and Mme. H. H. Kung, and which had died in the fall of 1945 from acute paralytic enteritis and peritonitis.

A report on the topographical anatomy of the brain was made by Mettler and Goss ('46) who concluded that externally it is identical with that of the bear. Unfortunately, practically no work has been done on the histological structure of the ursine brain making it impossible to compare its microscopic structure with that of the panda.

The panda brain was fixed in formalin, embedded in paraffin and sectioned at $30 \mu$. Alternate sections were stained in cresyl violet for cell study and in Weil for demonstration of fiber tracts. Another gross panda brain, also obtained from Pro-

${ }^{1}$ This investigation was aided by grants from the Horace H. Rackham School of Graduate Studies of the University of Michigan and from the A. B. Brower and E. R. Arn Medical Research and Scholarship Fund. 
fessor Mettler, was available for orientation. The photomicrographs used for the illustrations were made with the assistance of Mr. George J. Smith.

\section{THE OLFACTORY BULB}

Macroscopically, the olfactory bulb of the panda shows approximately the same general relationship in size and position to the hemisphere as do those of the better known carnivores such as the dog, the cat and the weasel. Unfortunately, most of the olfactory formation was lost from the bulbs, either during fixation or shipment to us. Where present it exhibits all of the usual layers, which form concentric rings around a patent ventricle. At some levels, the glomerular layer consists of two or three layers of small glomeruli; however, in the caudal part of the bulb, this becomes a single layer. The mitral cells are large, being about the same size as those found in the macaque. A third to a fourth of these cells are in the external plexiform layer. This large proportion of outwandered cells was also found in the weasel (Crosby and Humphrey, '39). Fewer granule cells are present in the mitral cell layer than in most other forms of mammals. Although an accessory bulb has been reported in other carnivores (cat, Fox, '40; weasel, Crosby and Humphrey, '39; mink, Jeserich, '45), one could not be identified in the present material due to the poor condition of the olfactory formation.

\section{THE ANTERIOR OLFACTORY NUCLEUS}

The posterior part of the olfactory bulb and the olfactory crus assume a triangular shape with the base placed ventrally. As one proceeds caudally, the first cells of the anterior olfactory nucleus appear dorsomedial to the ventricle. Because of its relationship farther caudally with the neopallial cortex, this dorsomedial portion may be considered a pars dorsalis of the nucleus. This position of pars dorsalis is the same as was found in the mink (Jeserich, '45). In the rabbit (Young, '36) and the pig' (Crosby and Humphrey, '39) pars dorsalis is 
the most rostral part of the anterior olfactory nucleus but appears dorsal to the ventricle, although in the bat (Humphrey, '36) it lies dorsolaterally. In other carnivores (Fox, '40, cat, and Crosby and Humphrey, '39, weasel) the most anterior portion of the nucleus is the part of pars lateralis located dorsolateral to the ventricle.

Farther caudally, the nucleus olfactorius anterior spreads out laterally around the ventricle to form its pars lateralis on the dorsolateral side and a well-developed pars ventralis across the base of the crus, which as the hemisphere is approached, shows signs of folding (figs. 1 and 2). In about the same plane in which pars ventralis first appeared, the anterior olfactory nucleus also swings around the medial end of the ventricle to form a ventromedially situated pars medialis (fig. 1). This is the least well-developed part of the nucleus in the panda. Just rostral to the junction of the crus with the hemisphere, pars ventralis becomes contiguous with pars medialis, thus completing the periventricular ring of gray. This ring of cells is found in most mammals, although not obviously present in the macaque (Lauer, '45) or man (Crosby and Humphrey, '41). In more caudal planes, a well-developed pars posterior appears directly below the ventricle at the point of junction between pars ventralis and pars medialis (figs. $3-5)$.

The caudal relationship of the various parts of the anterior olfactory nucleus with the hemisphere corresponds to that described in other forms. Pars dorsalis fuses with frontal cortex as the medial side of the crus becomes attached to the hemisphere. The continuity of pars lateralis, pars ventralis and pars medialis with the prepyriform cortex, tuberculum olfactorium and the anterior continuation of the hippocampus, respectively, can be demonstrated well out into the crus, with the last occurring most rostrally (fig. 2). In planes well posterior to the junction of the crus with the hemisphere, pars posterior grades over into the medial part of the deep layer of tuberculum olfactorium (fig. 5). 
A fairly well developed pars externa occurs in the panda (fig. 1). In planes of the crus where only a pars dorsalis can be seen, the most anterior cells of the pars externa can be found lying superficial to those of pars dorsalis, along the inner margin of the medial part of the lateral olfactory tract. They soon form a narrow band of cells, which, as one proceeds caudally, gradually swings over the apex of the crus, down its dorsolateral side and around the ventrolateral angle. The most caudal part of pars externa appears below the lateral portion of pars ventralis in planes just caudal to the junction of the crus with the hemisphere. It thus forms a semicircle around the dorsolateral half of the crus, although all parts of this semicircle cannot be demonstrated in any one section. Its position is very similar to that in the mink (Jeserich, '45). In the weasel pars externa is found principally on the lateral side of the crus (Crosby and Humphrey, '39) although Fox ('40) reported it only on the ventrolateral side in the cat. In the pig and the shrew it forms a complete ring around the ventricle and nearly so in the red squirrel (Crosby and Humphrey, '39). In some of the higher mammals such as the macaque (Lauer, '45) and in man (Crosby and Humphrey, '41) it appears to be entirely absent or represented perhaps by a few scattered cells.

\section{TUBERCULUM OLFACTORIUM}

The term tuberculum olfactorium as here used refers to that portion of the basal telencephalic wall which lies posterior to the anterior olfactory nucleus and is bounded caudally by the nucleus and the diagonal band of Broca. This conforms with the terminology used in papers on other mammals (see Gurdjian, '25; Loo, '31; Humphrey, '36; Fox, '40 ; Lauer, '45 ; and others) and man (Crosby and Humphrey, '41). The last paper contains an excellent discussion of the overlapping terminology used by various authors for this area.

In the panda there is no clear-cut demonstration between the caudal portion of the anterior olfactory nucleus and tuberculum olfactorium. In planes through the crus where the grav 
of that nucleus is completing its periventricular ring, the first indications of the tuberculum can be found between pars ventralis of the anterior olfactory nucleus and the surface of the crus at about the point where the caudal cells of pars externa disappeared (fig. 3). From there it spreads medially and to a slighter extent laterally, with pars ventralis merging into the deeper or polymorph layer of the tuberculum, as does pars posterior also, at more caudal levels.

Tuberculum olfactorium is quite extensive and well developed in the panda. Following Ramón y Cajal ('11), medial, intermediate and lateral parts may be distinguished. Of these the intermediate is the largest and best differentiated. In contrast to some forms such as the bat (Humphrey, '36), the macaque (Lauer, '45) and man (Crosby and Humphrey, '41) where the anterior portion of this part is thin or represented only by scattered cells, in the panda all three layers of tuberculum olfactorium can be distinguished well rostrally near its merger with pars ventralis of the anterior olfactory nucleus (figs. 3 and 4). Throughout its anterior half the plexiform layer is composed quite largely of fibers of the ventral part of the lateral olfactory tract. The pyramidal layer is characterized by small clusters of deeper staining fusiform and mediumsized pyramidal cells which form small projections from its superficial surface. The deeper polymorph layer is made up of scattered cells among which are a few of the large neurons mentioned by Obenchain ('25).

The lateral part of tuberculum olfactorium bends inward over the lateral olfactory tract (figs. 5-8). Its pyramidal layer contains a greater percentage of pyramidal cells than does that of the intermediate portion (as is also the case in the opossum, Loo, ' 31 ; the cat, Fox, ' 40 ; and the bat, Humphrey, '36) but with few fusiform cells present. As in the cat and bat, the polymorph layer is wider, coming into close proximity with the claustrum anteriorly and the putamen posteriorly.

The medial part of the tuberculum (figs. 6 and 7 ), which invades the medial wall of the hemisphere, appears better de- 
veloped than in most forms which have been reported. The plexiform layer, although slightly narrower, is well represented. Fewer pyramidal but more granule cells are present. The polymorph layer can be distinguished throughout except in the dorsal part which is occupied by the medial island of Calleja. Its deeper margin is indistinct due to its tendency to merge with the neighboring caudate and accumbens nuclei.

In the panda the characteristic islands of Calleja are fewer in number and much smaller in size than in other mammals with the possible exception of man (Crosby and Humphrey, '41). Practically no islands are found in the anterior third of the area (figs. 3-5). In the medial third small clusters of granule cells ean be seen in the polymorph layer or along the boundary between this layer and the overlying putamen and caudate nucleus (figs. 6 and 7). Three or 4 small, irregular masses of granule cells occur in the plexiform layer, the larger of these lying at the medioventral angle of the hemisphere. The medial island of Calleja (fig. 7) is greatly reduced in size and extent. Only a few small scattered clusters of granule cells are found in the caudal part of tuberculum olfactorium (fig. 8).

NUCLEI OF THE VENTROMEDTAL HEMISPHERE WALL

In general the nuclei included in this group are those lying rostral and dorsal to lamina terminalis (or to pre-optic area), including septum pellucidum. A discussion of the varied terminologies applied to this region can be found in the text by Ariëns Kappers, Huber and Crosby ('36) and Loo ('41). A few nuclear groups are included here which extend outside of this area but which are in part closely associated with it.

\section{Lateral septal nucleus}

This, as in other mammals, is the largest of the septal nuclei in the panda. It extends from a point rostrally, between the anterior continuation of the hippocampus and the lateral ventricle, to a point behind the foramen of Munro (figs. 6-8). 
As in the opossum (Loo, '31), mink (Jeserich, '45) and macaque (Lauer, '45), the nucleus may be divided into dorsal and ventral portions. The ventral part merges with nucleus accumbens rostrally and with the bed nuclei of the anterior commissure and of stria terminalis caudally, its cells resembling those of the underlying groups. In the dorsal section of the lateral septal nucleus, the cells are pyramidal or fusiform in appearance and are larger and more scattered in arrangement than in the ventral part. Caudally there is no line of demarcation between this nucleus and nucleus septo-fimbrialis, except, perhaps, that the latter has a larger percentage of spindle-shaped cells.

\section{Medial septal nucleus}

Various investigators have divided this nucleus into two parts. Loo ('31), Fox ('40) and Lauer ('45) described smallcelled anterior and large-celled posterior parts in the opossum, the cat and the macaque, although Jeserich ('45) reports an indistinct separation into dorsal and ventral parts in the mink. No division of this nucleus was found by Humphrey ('36) in the bat. In the panda the rostral end is composed of smaller cells which extend caudally as a narrow band on the dorsal side of the nucleus. Most of the nucleus is composed of large cells similar to those of the nucleus of the diagonal band of Broca with which the medial septal nucleus fuses ventrally (figs. 7 and 8).

\section{Nucleus of diagonal band of Broca}

There is no clear-cut separation between this nucleus and the medial septal nucleus. Although its dorsal limit is usually placed approximately opposite to the dorsal margin of nucleus accumbens, Loo ('41) did not extend it much beyond the medioventral angle of the hemisphere. In the panda the rostral end of the nucleus lies medial to nucleus accumbens (fig. 7), from which position it spreads slightly dorsally to meet the medial septal nucleus. Caudally it swings ventrally and laterally 
behind tuberculum olfactorium (figs. 8 and 9). Here it divides into two bands of cells, one of which extends laterally to the region of the anterior amygdaloid area, and the other swings dorsolaterally toward the ventral border of the putamen and the lateral part of globus pallidus to merge with nucleus ansae lenticularis. This division of the nucleus into two arms corresponds with the conditions in other forms, although Humphrey ('36) makes no mention of a dorsal portion in the bat.

\section{Nucleus septo-fimbrialis}

This nucleus is located in the dorsolateral part of the septal area between the column of the fornix and the lateral ventricle. Anteriorly it is not distinguishable from the dorsal part of the lateral septal nucleus with which it merges, as is also the condition in the rabbit (Young, '36). Caudally it gradually fades out among the lateral fibers of the fornix. Jeserich ('45) made no mention of this nucleus in the mink, but it has been reported in other forms. Fox ('40) found the nuclei of the two sides meeting in the midline posteriorly, but they are always well separated by the fornix columns in the panda. In lower forms this nucleus was considered as part of primordium hippocampus by Johnston ('13) and as the caudal end of the lateral septal nucleus in lizards by Herrick ('10). Fox ('40) also refers to it as the posterior extension of the lateral septal nucleus in the cat. In the panda there is considerable resemblance between the cells of the two nuclei, but there are more fusiform cells in nucleus septo-fimbrialis, particularly in its dorsal portion.

\section{Nucleus triangularis}

Situated in the midplane between the fornix columns ventrally and the hippocampal commissure dorsally, with many of its cells interspersed among the fibers of the latter, the nucleus triangularis may be considered as a part of the bed nucleus of the hippocampal commissure. Humphrey ('36) referred to it as the precommissural portion of the bed nucleus. 
Young ('36) and Loo ('41) also considered it as part of this nucleus. Johnston ('13) figured it as part of primordium hippocarnpus in the rat. This nucleus, composed of small, pale-staining cells, is quite extensive in the panda. In some sections it is in continuity with nucleus septo-fimbricalis dorsolaterally but can be distinguished from the latter by type of cell and difference in staining.

\section{Vestigial remnants of the hippocampus}

The so-called anterior continuation of the hippocampus, which is a forward extension of indusium griseum, is quite prominent in the panda (figs. 1-6). As in the cat (Fox, '40) and macaque (Lauer, '45), after passing over the genu of corpus callosum it forms a double curve, sweeping posteriorly below corpus callosum and then ventrally and anteriorly, behind and below the frontal cortex. Anteriorly it extends farther forward into the olfactory crus than it apparently does in other forms, forming there a distinct cluster of cells just medial to pars medialis of the anterior olfactory nucleus (fig. 1).

At the caudal end of the rostrum of corpus callosum, a small stream of cells extends from the anterior continuation of the hippocampus first dorsorostrally and then caudally to form a small nucleus below the body of corpus callosum, separated from the nucleus of the other side by the precommisural fornix. More caudally the nucleus lies farther laterally between the body of the fornix and corpus callosum. This represents nucleus septo-hippocampus in the panda (Ariëns Kappers, Huber and Crosby, '36; Young, '36; Humphrey, '36). It corresponds to nucleus septalis dorsalis of Loo ('31 and '41). As in the cat (Fox, '40), mink (Jeserich, '45) and macaque (Lauer, '45), this nucleus in the panda contains in many sections only a few cells. In one place on the right side, however, the nucleus becomes quite prominent, forming a distinct cluster of cells at the dorsomedial angle of the ventricle. On the other side there is a slight increase in the number of cells per section, but the nucleus remains in its customary position. 


\section{Bed nuclei of the anterior commissure and stria terminalis}

As in other mammalian forms which have been reported, a condensation of small cells surrounds the rostral half of the anterior commissure and constitutes its bed nucleus. Dorsally there is no line of demarcation between this bed nucleus and the lateral septal nucleus rostrally. Caudally the former merges with the bed nucleus of stria terminalis and then, ventral to the commissure, passes over into the anterior part of the preoptic area (figs. 9 and 10).

The extent of the bed nucleus of stria terminalis varies in different animals. In the opossum, Loo ('31) found it along the entire extent of the tract. Humphrey ('36), in the bat, described only scattered cells in the caudal portion, and Fox ('40) reported it only as far caudally as the anterior nucleus of the thalamus in the cat. In the panda it is quite prominent throughout the rostral part of stria terminalis but dwindles to a few cells along the caudal portion of the fiber tract.

THE AMYGDALOID COMPLEX

Of the various carnivore amygdalae which have been described (e.g., Foetorius furo, Völsch, '10; cat, Fox, '40; mink, Jeserich, '45), the amygdala of the panda most closely resembles that of the cat, from which it differs, however, in several respects. For purposes of description, the complex has been divided into 4 groups: (1) an anterior amygdaloid area, (2) a baso-lateral group, (3) a cortico-medial group, and (4) a cortico-amygdaloid transition area. This is the same plan as followed by Humphrey ('36), Crosby and Humphrey ('41 and '44) and Lauer ('45). Fox ('40), however, used only three divisions in the cat, and placed the nucleus of the lateral olfactory tract with the anterior amygdaloid area instead of the cortico-medial group.

\section{Anterior amygdaloid area}

This term has been used by various investigators to designate an area of undifferentiated gray at the rostral end of the 
amygdaloid complex, which passes over caudally into various nuclear masses. In the panda it extends from the anterior tip of the temporal lobe caudally to planes through the caudal part of the optic chiasma (figs. 9 and 10). Its dorsomedial border is in direct continuity with the nucleus of the diagonal band of Broca. Dorsally and dorsolaterally there is no break between this area and the substriatal gray, except that the latter region is distinguished by scattered large neurons. Caudally the anterior amygdaloid area is encroached upon by the various amygdaloid nuclei until the posterior end becomes indistinguishable from the deeper part of the medial nucleus.

\section{Cortico-medial amygdaloid group}

The amygdaloid complex proper of the panda is divided about equally between the cortico-medial and baso-lateral groups with the former group extending from the anterior end of the complex to the rostral limit of the hippocampus. The cortico-medial group may be divided into cortical, medial and central nuclei and a nucleus of the lateral olfactory tract as are found in other forms. In addition there is another small mass designated as the superficial nucleus.

Nucleus of the lateral olfactory tract (figs. 9 and 10). The large cells of this nucleus form a discrete oval mass in the dorsomedial part of the amygdaloid complex. As in the cat (Fox, '40) its rostral end forms a rounded elevation on the surface of the brain in the panda just medial to the ventromedial angle. Further caudally it is surrounded on three sides by the anterior amygdaloid area although dorsomedially it is in intimate association with the dorsal limb of the nucleus of the diagonal band of Broca and the substriatal gray. In the panda, as in the cat (Fox, '40) and the mink (Jeserich, '45), the nucleus of the lateral olfactory is not broken up into subdivisions as reported in most other forms. As in the cat there is a clumping of cells between the medial and cortical nuclei for a few sections caudal to the position of the main nuclear mass which perhaps indicates a posterior portion of the nucleus. 
Medial amygdaloid nucleus (figs. 11 and 12). As one proceeds caudally from the rostral end of the complex, there is a condensation of the superficial cells of the anterior amygdaloid area around the ventromedial angle of the hemisphere which becomes the medial amygdaloid nucleus. Farther from the surface the cells are less densely arranged and are never clearly separated from the anterior amygdaloid area where the latter area is present. Caudally the nucleus tapers down to a narrow band of cells lying along the ventral surface of the optic tract and gradually disappears near the caudal end of the complex. In part it is separated from the central, basal and accessory basal nuclei by small intercalated masses. The medial nucleus is composed of small to medium-sized cells of various types.

Central amygdaloid nucleus (figs. 11-13). This nucleus lies on the dorsal side throughout the caudal half of the amygdaloid complex. Where the medial nucleus is present, the central nucleus is separated from it by the accumulating fibers of stria terminalis. Although the central nucleus is divided from the underlying basal and lateral nuclei by small intercalated masses, dorsally it is in contact with the substriatal gray and nucleus ansae lenticularis. Laterally and dorsolaterally it is in direct continuity with the putamen, the large scattered cells of which distinguish it from the central nucleus. Near its caudal end a group of larger cells can be found in the dorsomedial part of the central nucleus (fig. 13), as has been previously reported in the cat (Fox, '40), mink (Jeserich, '45) and rat (Brodal, '47).

Cortical amygdaloid nucleus (figs. 9-13). The cortical nucleus is the largest and best developed of the cortico-medial group. It is present throughout nearly the entire length of the complex, being absent only at the extreme rostral end and for a short distance at the posterior pole where it is replaced by the hippocampus. It is the most ventral nucleus and occupies the ventromedial angle of the complex. As in the cat (Fox, '40), its superficial surface, in part, presents a corrugated appearance, although this is more prevalent in the rostral part of the nucleus than in the caudal part as in the cat. 
There is no clear division between this nucleus and the corticoamygdaloid transition area lateral to it and the accessory basal nucleus which is dorsolateral. Although it is in close contact with the medial nucleus, the extent of the cortical nucleus can be clearly outlined by the relatively dense superficial layer of pyramidal cells. Through much of its extent it forms a horseshoe-shaped mass from the hilus of which fibers can be seen streaming dorsally.

Superficial amygdaloid nucleus (fig. 10). At the rostral end of the complex there is a narrow band of pale staining cells in the outer part of the molecular layer around the ventromedial angle of the hemisphere. Nearly all of the cells are small and spindle-shaped, with their long axes at right angles to the surface of the brain. Scattered among them are a few larger neurons. No mention is made of a similar group in other accounts.

\section{Baso-lateral amygdaloid group}

This group which occupies the lateral and ventrolateral half of the amygdaloid complex is composed of well-developed basal and lateral amygdaloid nuclei and a smaller accessory basal nucleus. The intercalated masses are also included in this group.

Basal amygdaloid nucleus (figs. 11-13). Although the basal amygdaloid nucleus is the most anterior of the baso-lateral group, it does not extend so far rostrally as do the nuclei of the cortico-medial group. It occupies a central position in the complex and extends posteriorly to the anterior end of the hippocampus. It is clearly divisible into large and small-celled portions. However, whereas the large-celled part in most mammals lies lateral or dorsolateral to the small-celled part, in the panda it is directly dorsal. The small-celled part is not separated on its medial side from the accessory basal nucleus and the cortico-amygdaloid transition area. In the caudal portion of the amygdaloid complex, this ventral small-celled area is demarcated from the lateral amygdaloid nucleus and, in 
part, from the large-celled part of the basal nucleus by a large bundle of fibers which stream into (or out of) both parts of the basal nucleus from the external capsule (figs. 12 and 13). Accessory basal amygdaloid nucleus (fig. 11). This nucleus is never clearly detached from the medial side of the basal nucleus. There are places, however, where there is some indication of separation, this being more evident dorsally than ventrally. Although the whole mass is much smaller than either the basal or lateral nuclus it can be clearly divided, like the basal, into a dorsal and a ventral part. The cells of the dorsal portion are larger, but not so large as those of the dorsal section of the basal amygdaloid nucleus.

The accessory basal amygdaloid nucleus is apparently much more definite in the panda than in other carnivores. It was not reported by Fox ('40) in the cat and is only represented by scattered cells in the mink (Jeserich, '45). In other animals it may be absent or poorly defined as in the rabbit (Young, '36), the rat (Brodal, '47) and Caenolestes (Obenchain, '25), consist of only one part as in Tamandua (Smith, '30) and the bat (Humphrey, '36), or of two parts as in shrew (Crosby and Humphrey, '41).

Lateral amygdaloid nucleus (figs. 11-13). The lateral amygdaloid nucleus is the largest and most extensive cell mass of the complex. Lying lateral and dorsolateral to the basal nucleus, it extends from a plane slightly behind the rostral end of the basal nucleus to a position well caudal to that of any of the other nuclear groups with the possible exception of the central nucleus. Posteriorly it is separated from the hippocampus by the inferior horn of the lateral ventricle. Throughout its extent, but particularly in its anterior half, a wedge-shaped mass of cells projects upward from its dorsolateral margin among the fibers of the external capsule. Bands of fibers entering or leaving the external capsule, divide this wedge into smaller islands in which the cells are more densely arranged and perhaps slightly larger than in the main part of the nucleus. This would correspond to conditions in the mink (Jeserich, '45) and is perhaps comparable to the 
anterior and posterior parts of the lateral nucleus in the rabbit (Young, '36).

Intercalated cell masses (figs. 11 and 12). As in practically all other forms studied, intercalated cell masses are found in the panda. The individual clusters are small. The most constant mass lies in the usual position between the central nucleus and the dorsal tips of the basal and lateral amygdaloid nuclei. Another occurs between the central and medial nuclei in conjunction with the fibers of stria medullaris.

Cortico-amygdaloid transition area (figs. 11-13). Situated in the ventral part of the amygdaloid complex is a mass of mixed cells which shows close relationship with the pyriform cortex and the cortical amygdaloid nucleus ventrally and with the baso-lateral group of nuclei dorsally. This relationship has been observed in various forms from opossum to man (Johnston, '23; Hilpert, '28; Crosby and Humphrey, '41 and '44; Lauer, '45; Brodal, '47; and others). It was interpreted by Johnston ('23) as indicating that the formation of the basolateral group and the cortical nucleus came about through an infolding of the pyriform lobe cortex. Crosby and Humphrey ('41) indicate that conditions in the human amygdaloid complex support this belief or at least show an intimate functional relation. This area in the panda is relatively large and has no delimitation from the pyriform cortex laterally, the cortical nucleus medially and the ventral portion of the basal and lateral nuclei dorsally and dorsolaterally.

\section{GENERAL SUMMARY AND DISCUSSION}

The giant panda shows well-developed olfactory areas. The olfactory bulb is large with a stocky, triangular crus. Due to the loss of most of the olfactory formation in the preparation of this brain, it could not be determined if an accessory olfactory bulb was present as in other carnivores. Where remnants of the olfactory formation remain, they show the typical layers of the mammalian olfactory formation.

The anterior olfactory nucleus is well differentiated, forming a complete ring of gray around the olfactory ventricle. 
This ring can be divided into the customary dorsal, lateral, ventral and medial portions, although they tend to be somewhat medially rotated around the ventricle from their usual position, due to the fact that it is the dorsomedial and not the dorsal side of the crus which becomes attached to the hemisphere. A pars externa of the nucleus can be identified on the lateral and ventral surfaces. Pars posterior is exceedingly large, occupying a position ventromedial to the ventricle, corresponding to that of nucleus accumbens more caudally. The various parts of the anterior olfactory nucleus exhibit their typical relationships with the gray of the hemisphere, the transition taking place farther rostrally than is common in most forms.

The tuberculum olfactorium is well developed, showing three layers throughout its extent. Although islands of Calleja are present, they are few in number and consist primarily of small clusters of granule cells along the superficial surface. In no other mammal, except perhaps man (Crosby and Humphrey, '41), do they appear to be as scarce. Even the medial island of Calleja is relatively small in contrast to other forms.

In the septal region of the hemisphere the following nuclei were identified - medial and lateral septal nuclei, nucleus accumbens, nucleus triangularis, nucleus septo-fimbrialis, nucleus of the diagonal band of Broca and bed nuclei of stria terminalis and of the anterior commissure. Of these nuclear masses the lateral septal nucleus is the largest. Ventrally this nucleus merges with nucleus accumbens rostrally and with the bed nuclei of stria terminalis and of the anterior commissure caudally. Posteriorly it is continued behind the foramen of Munro by the nucleus septo-fimbrialis which differs slightly from it in cell content. The medial septal nucleus is much smaller and is continuous with the nucleus of the diagonal band of Broca ventrally.

The septo-hippocampal nucleus is represented by a small stream of cells which extends along the ventral surface of corpus callosum from the anterior continuation of the hippocampus rostrally to the hippocampus proper caudally. The 
nucleus of the diagonal band of Broca appears to be exceptionally well developed and extends from the ventral part of the medial septal nucleus caudolaterally behind tuberculum olfactorium to eventually merge laterally with the anterior amygdaloid area and the substriatal gray.

The amygdaloid complex shows marked resemblance to that of the cat (Fox, '40) but with an apparently greater development of the baso-lateral group of nuclei. The nucleus of the lateral olfactory tract is large but is found in the dorsomedial part of the complex and not in the customary position between the medial and cortical nuclei. Of the cortico-medial group, the cortical nucleus is exceedingly well developed. Of the baso-lateral group, the basal and lateral nuclei are well differentiated and a less well defined accessory basal nucleus can be identified.

A comparatively large undifferentiated area, called the cortico-amygdaloid transition area, exists between the pyriform cortex laterally, the cortical amygdaloid nucleus medially and dorsomedially, and the baso-lateral group of nuclei dorsolaterally. This perhaps indicates that these areas have a common genetic origin as has been suggested previously by Johnston ('23), Crosby and Humphrey ('41) and others.

\section{LITERATURE CITED}

Ariëns Kappers, C. U., G. C. Huber and E. C. Crosbt 1936 The comparative anatomy of the nervous system of vertebrates, including man. The Macmillan Co., New York.

Brodal, A. 1947 The amygdaloid nueleus in the rat. J. Comp. Neur., 87 : 1-16. CRosBy, E. C., AND T. HUMPHREY 1939 Studies of the vertebrate telencephalon. I. The nuclear configuration of the olfactory and accessory olfactory formations and the nucleus olfactorius anterior of certain reptiles, birds and mammals. J. Comp. Neur., $71: 121-213$.

1941 Studies of the vertebrate telencephalon. II. The nuclear pattern of the anterior olfactory nucleus, tuberculum olfactorium and the amygdaloid complex in adult man. J. Comp. Neur., 74: 309-352.

1944 Studies of the vertebrate telencephalon. III. The amygdaloid complex in the shrew (Blarina brevicauda). J. Comp. Neur., 81: 285305.

Fox, C. A. 1940 Certain basal telencephalic centers in the cat. J. Comp. Neur., 72: $1-62$. 
GURDJIAN, E. S. 1925 Olfactory connections in the albino rat, with special reference to the stria medullaris and the anterior commissure. J. Comp. Neur., 38: 127-163.

HERRICK, C. J. 1910 The morphology of the forebrain in Amphibia and Reptilia. J. Comp. Neur., 20: 413-547.

Hilpert, P. 1928 Der Mandelkern des Menschen. I. Cytoarchitektonik und Faserverbindungen. J. f. Psychol. und Neur., 36:44-74.

HuMphrey, T. 1936 The telencephalon of the bat. I. The non-cortical nuelear masses and certain pertinent fiber connections. J. Comp. Neur., 65: $603-711$.

JESERICH, M. W. 1945 The nuclear pattern and the fiber connections of certain non-cortical areas of the telencephalon of the mink (Mustela vison). J. Comp. Neur., 83: 173-211.

Johnston, J. B. 1913 The morphology of the septum, hippocampus, and pallial commissures in reptiles and mammals. J. Comp. Neur., 23: 371-478. 1923 Further contributions to the study of the evolution of the forebrain. $J$. Comp. Neur., $35: 337-481$.

LAUER, E. W. 1945 The nuclear pattern and fiber connections of certain basal telencephalic centers in the Macaque. J. Comp. Neur., 82: 215-254.

Loo, Y. T. 1931 The forebrain of the opossum, Didelphis virginiana. Pt. II. J. Comp. Neur., $52:$ 1-148.

1941 The mammalian endbrain. I. The septum. Contr. Biol. Lab. Sc. Soc. China, 15: 29-69.

MetTler, F. A., AND L. J. Goss 1946 The brain of the giant panda (Ailuropoda melanoleuca). J. Comp. Neur., 84: 1-9.

Orenchain, J. B. 1925 The brains of the South American marsupials Caenolestes and Orolestes. Publ. 224 of Field Museum of Natural History, Zool. Series, $14: 175 \sim 232$.

RAMrón y CAJAL, S. 1911 Histologie du système nerveux de I'homme et des vertébrés. A. Maloine, Paris. 2 vol.

SuIth, O. C. 1930 The corpus striatum, amygdala, and stria terminalis of Tamandua tetradactyla. J. Comp. Neur., 51: 65-127.

VöLsch, M. 1910 Zur rergleichenden Anatomie des Mandelkerns und seiner Nachbargebilde. II. Teil. Arch. f. mikr. Anat., 76:373-523.

Youna, M. W. 1936 The nuclear pattern and fiber connections of the noncortical centers of the telencephalon of the rabbit. J. Comp. Neur., $65: 295-401$.

\section{ABBREVIATIONS}

ANT.AMYG.A., anterior amygdaloid COM.ANT.L.ANT., anterior limb of area. anterior commissure.

ANT.CON.HIP., anterior continuation of hippoeampus.

CAP.EXT., external capsule.

CAP.INT., internal capsule.

CH.OP., optic ehiasma.

CLAUS., claustrum.

COM.ANT., anterior commissure. CORP.CAI., corpus callosum.

CORT.AMYG.TR.A., cortico-amygdaloid transition area.

CORT.PREPYR., prepyriform cortex.

CORT.PYR., pyriform cortex.

FOR., fornix.

F.RHIN., rhinal fissure. 
GL.PAL., globus pallidus.

G.RECT., gyrus rectus.

HIP., hippocampus.

IND.GR, indusium griseum.

ISL.CAL., islands of Calleja.

ISL.CAL.M., medial island of Calleja.

M.INTER., interealate mass.

NUC.ACC., nucleus aceumbens.

NUC.AMYG.BAS.ACC.P.I.AT., lateraI part of accessory basal amygdaloid nucleus.

NUC.AMYG.BAS.ACC.P.MED., medial part of accessory basal amygdaloid nucleus.

NUC.AMYG.BAS.P.LAT., lateral part of basal amygdaioid nucleus.

NUC.AMYG.BAS.P.MED., medial part of basal amygdaloid nucleus.

NUC.AMYG.CENT.P.LAT., lateral part of central amygdaloid nucleus.

NUC.AMYG.CENT.P.MED., medial part of central amygdaloid nucleus.

NUC.AMYG.CORT., cortical amygdaloid nucleus.

NUC.AMYG.LAT., lateral amygdaloid nucleus.

NUC.AMYG.MED., medial amygdaloid nucleus.

NUC.AMYG.SUP., superficial amygdaloid nucleus.

NUC.CAUD, caudate nucleus.

NUC.COM.ANT., bed nucleus of anterior commissure.

NUC.D.B.B., nucleus of the diagonal band of Broca.

NUC.OLF.ANT.P.DOR., dorsal part of anterior olfactory nucleus.

NUC.OLF.ANT.P.EXT., external part of anterior olfactory nucleus.
NUC.OLF.ANT.P.LAT., lateral part of anterior olfactory nucleus.

NUC.OLF.ANT.P.MED., medial part of anterior olfactory nucleus.

NUC.OLF.ANT.P.POST., posterior part of anterior olfactory nucleus.

NUC.OLF.ANT.P.VENT., ventral part of anterior olfactory nucleus.

NUC.PREOP.LAT., lateral preoptic nucleus.

NUC.PREOP.MED., medial preoptic nucleus.

NUC.SEPT.LAT., lateral septal nucleus.

NUC.SEPT.LAT.P.DOR., dorsal part of lateral septal nueleus.

NUC.SEP'T.LAT.P.VENT., ventral part of lateral septal nucleus.

NUC.SEPT.MED., medial septal nueleus.

NUC.ST.TERM., bed nucleus of stria terminalis.

NUC.SUPRAOP., supraoptic nucleus.

NUC.TR.OLF.LAT., nueleus of lateral olfactory tract.

PUT., putamen.

ST.TERM., stria terminalis.

SUB.INOM., substantia innominata.

TR.OLF.LAT,, lateral olfactory tract.

TR.OP., optic tract.

TUB.OLF., tubereulum olfactorium.

TUB.OLF.L.PLEX., plexiform layer of tuberculum olfactorium.

TUB.OLF.L.POLY., polymorph layer of tuberculum olfactorium.

TUB.OLF.L.PYR., pyramidal layer of tuberculum olfactorium.

V.III, third ventricle.

V.LAT., lateral ventricle.

V.OLF., olfactory ventricle. 


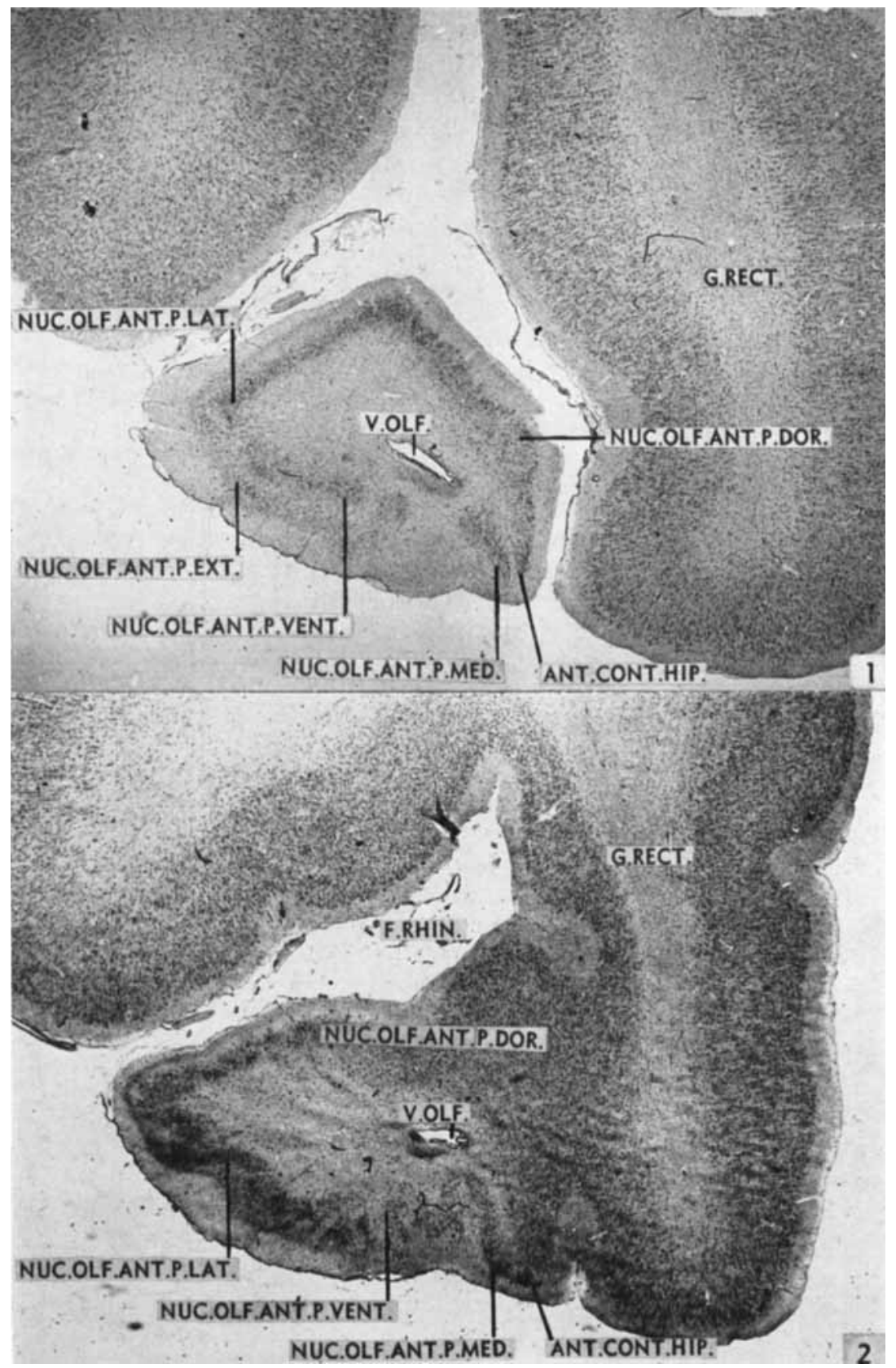

Figs. 1 and 2 Sections through the olfactory crus showing the formation of the anterior olfactory nucleus. $\times 10$. 


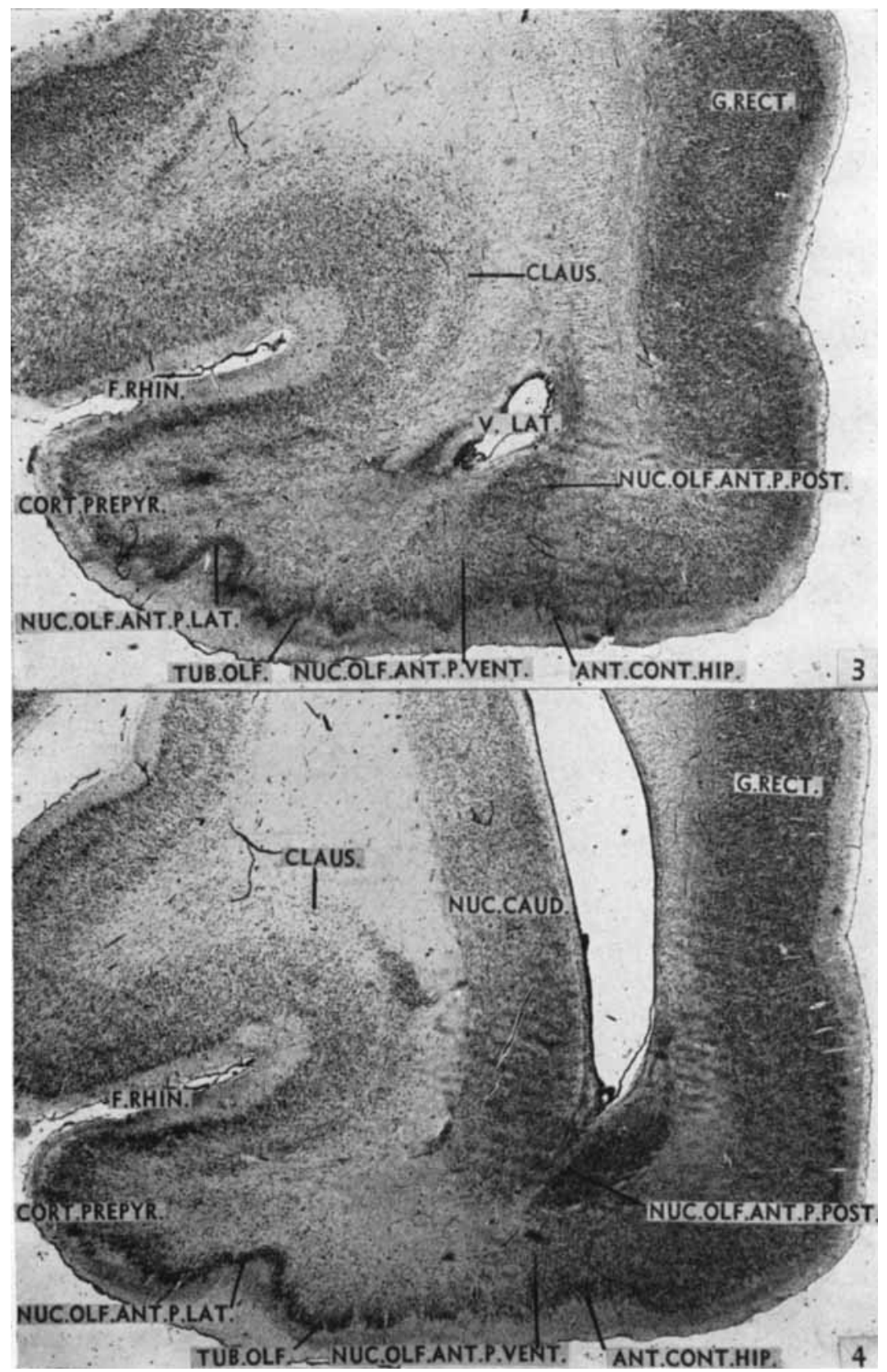

Figs. 3 and 4 Sections through the caudal end of the anterior olfactory nueleus and the rostral part of tuberculum olfactorium. $\times 10$. 


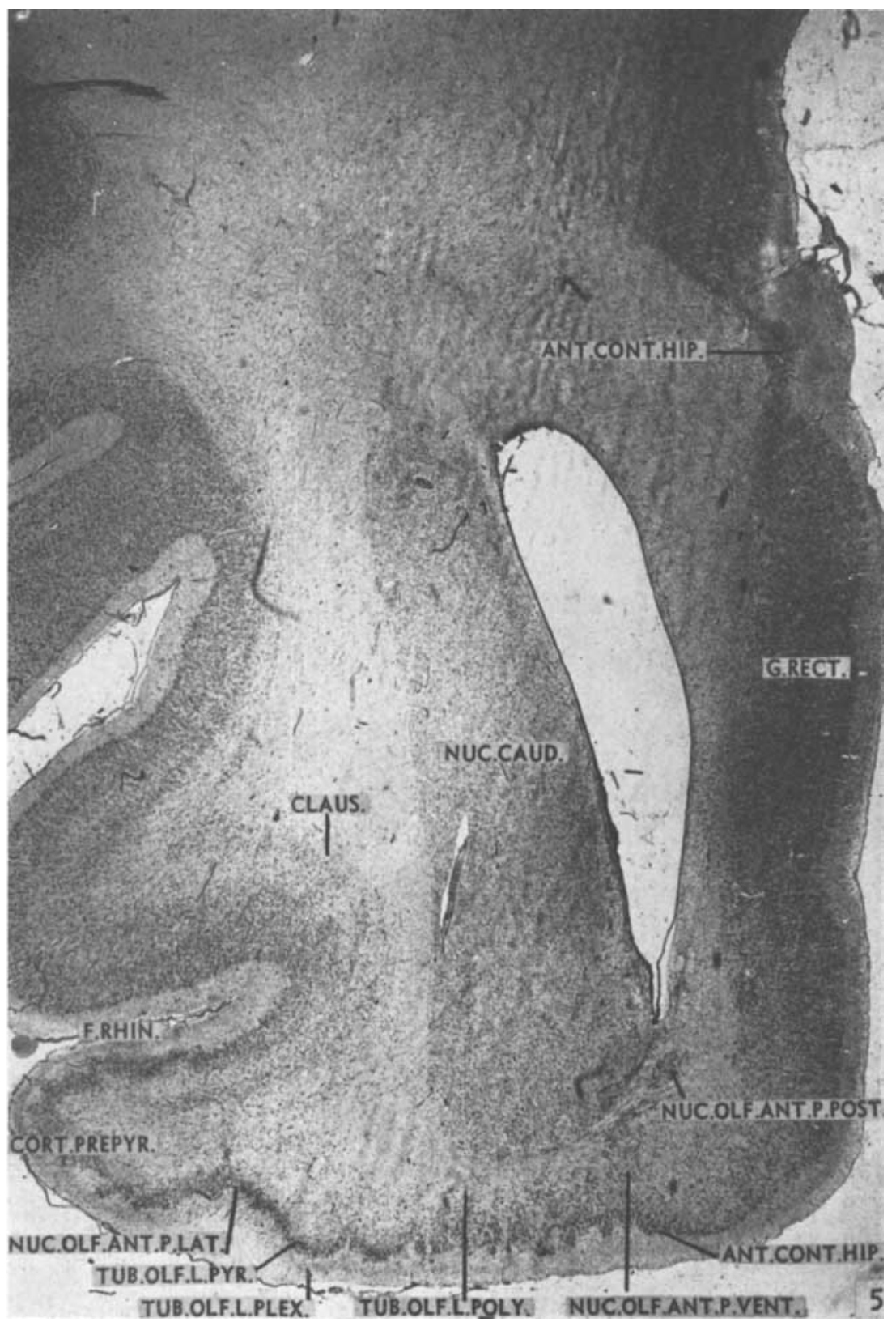

Fig. 5 Section through tuberculum olfactorium $\frac{1}{2} \mathrm{~mm}$ eaudal to figure $4 . \times 10$. 


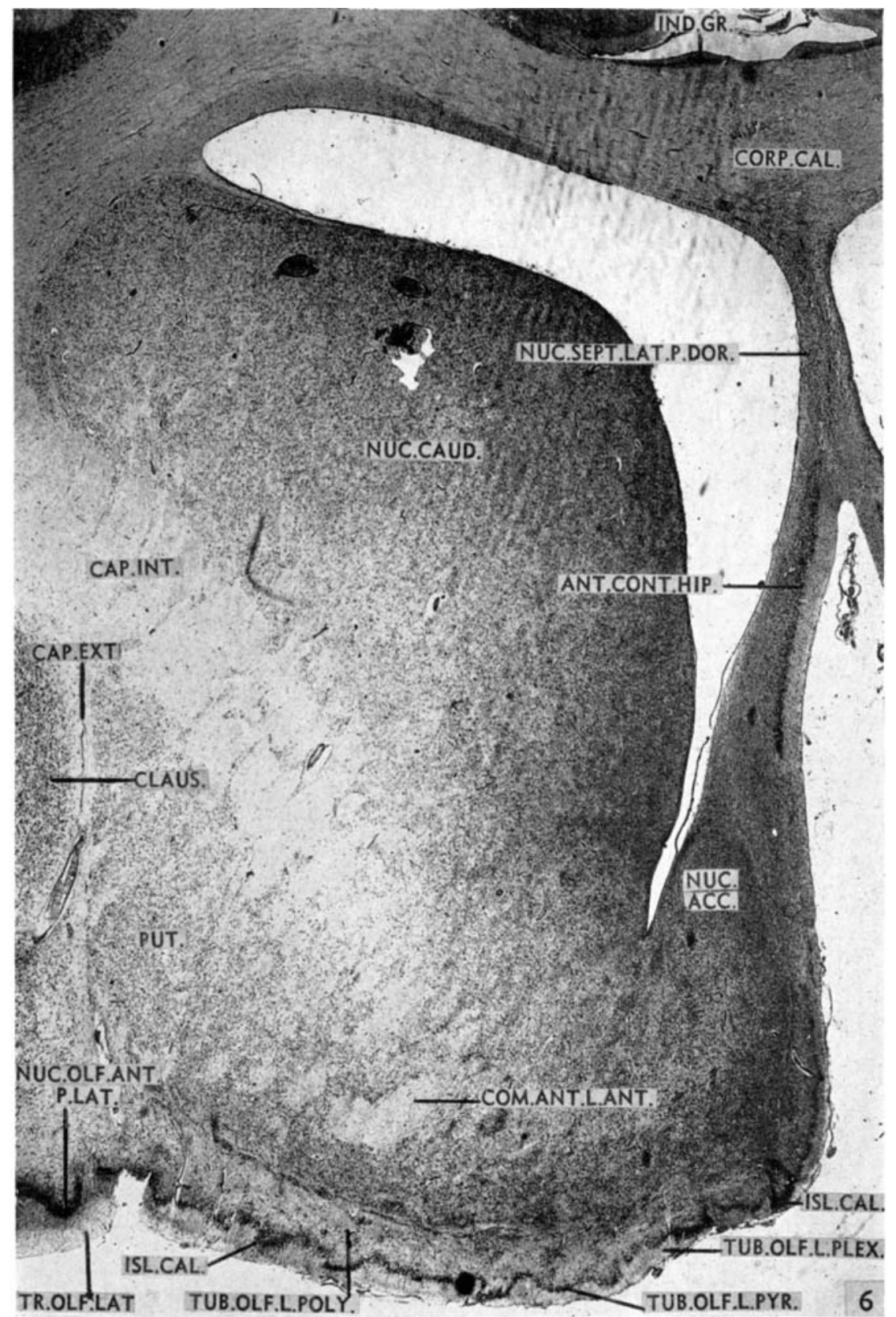

Fig. 6 Section at the level of the anterior end of the lateral septal nucleus, about $5 \mathrm{~mm}$ caudal to figure $5 . \times 10$. 


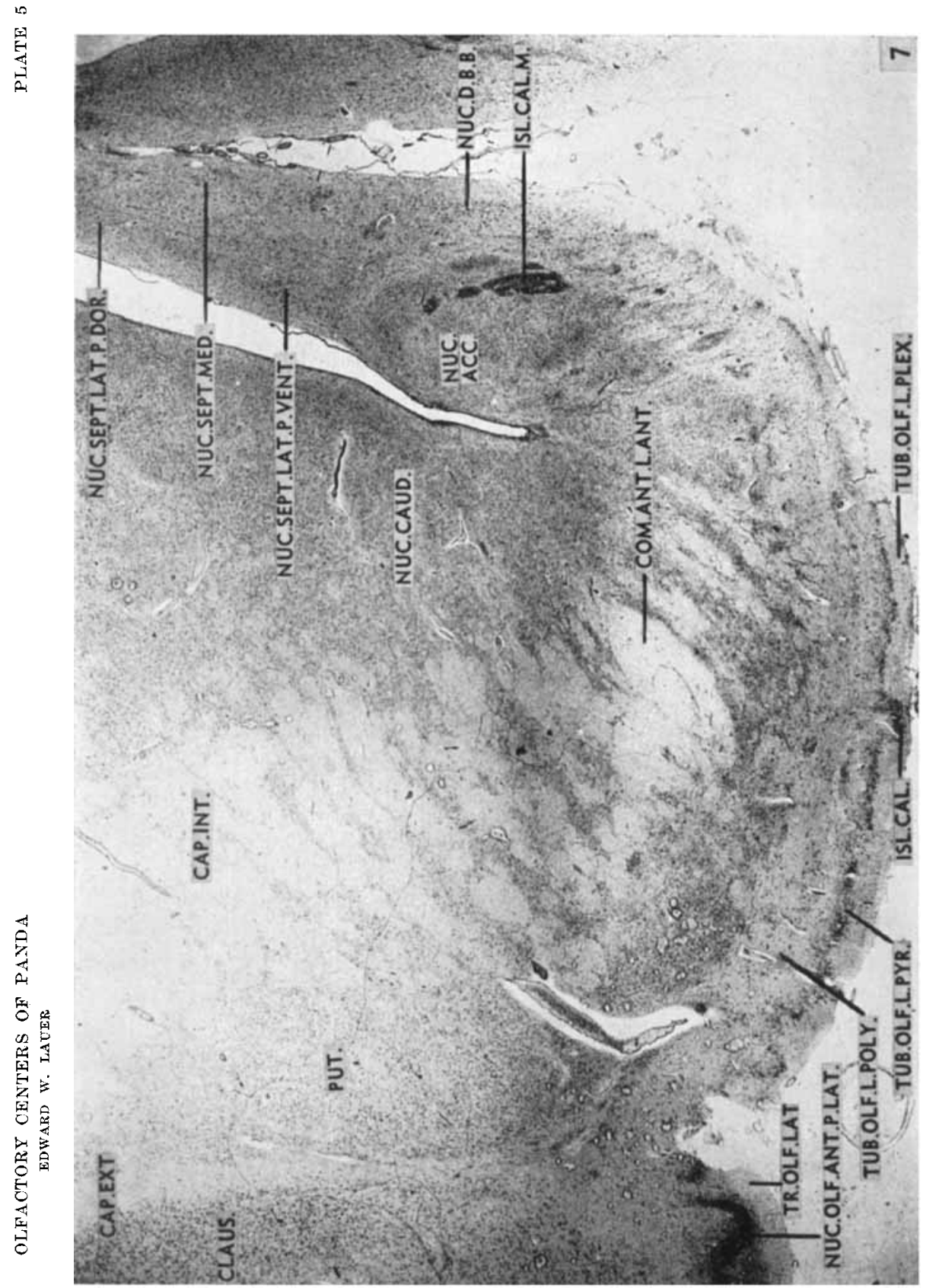

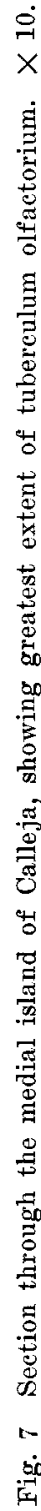




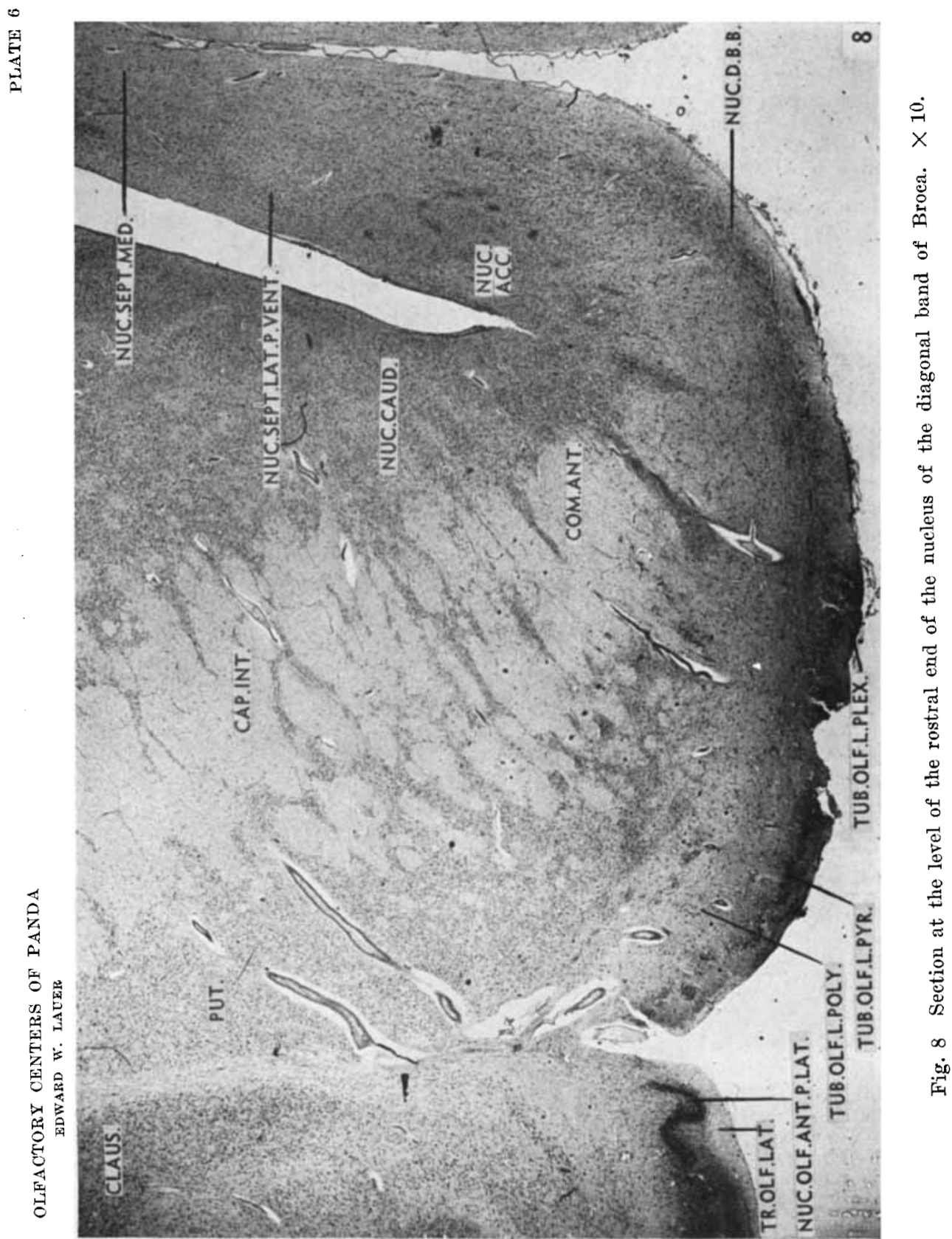




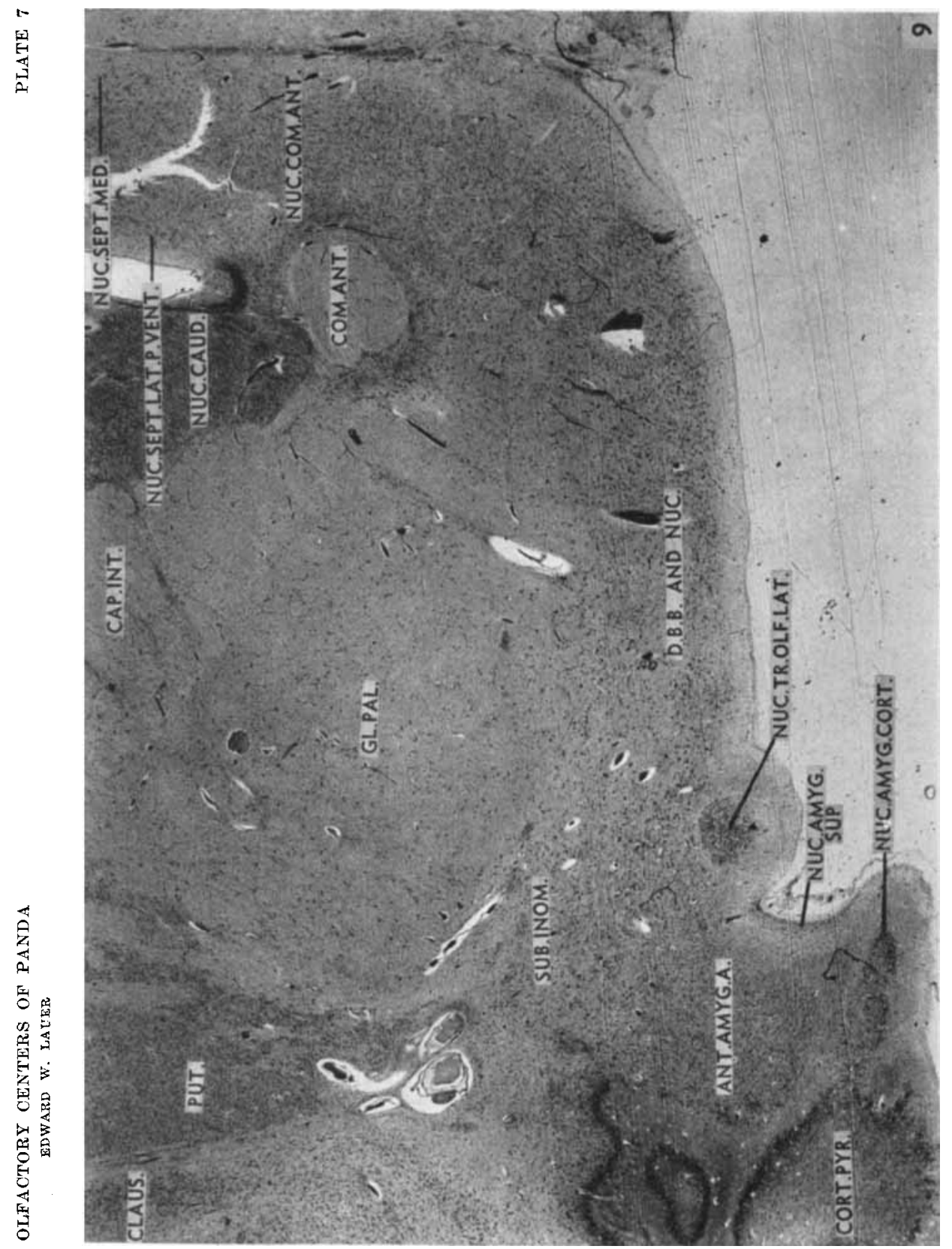

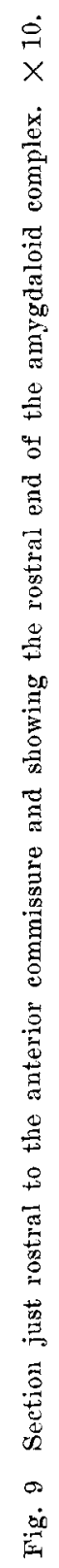




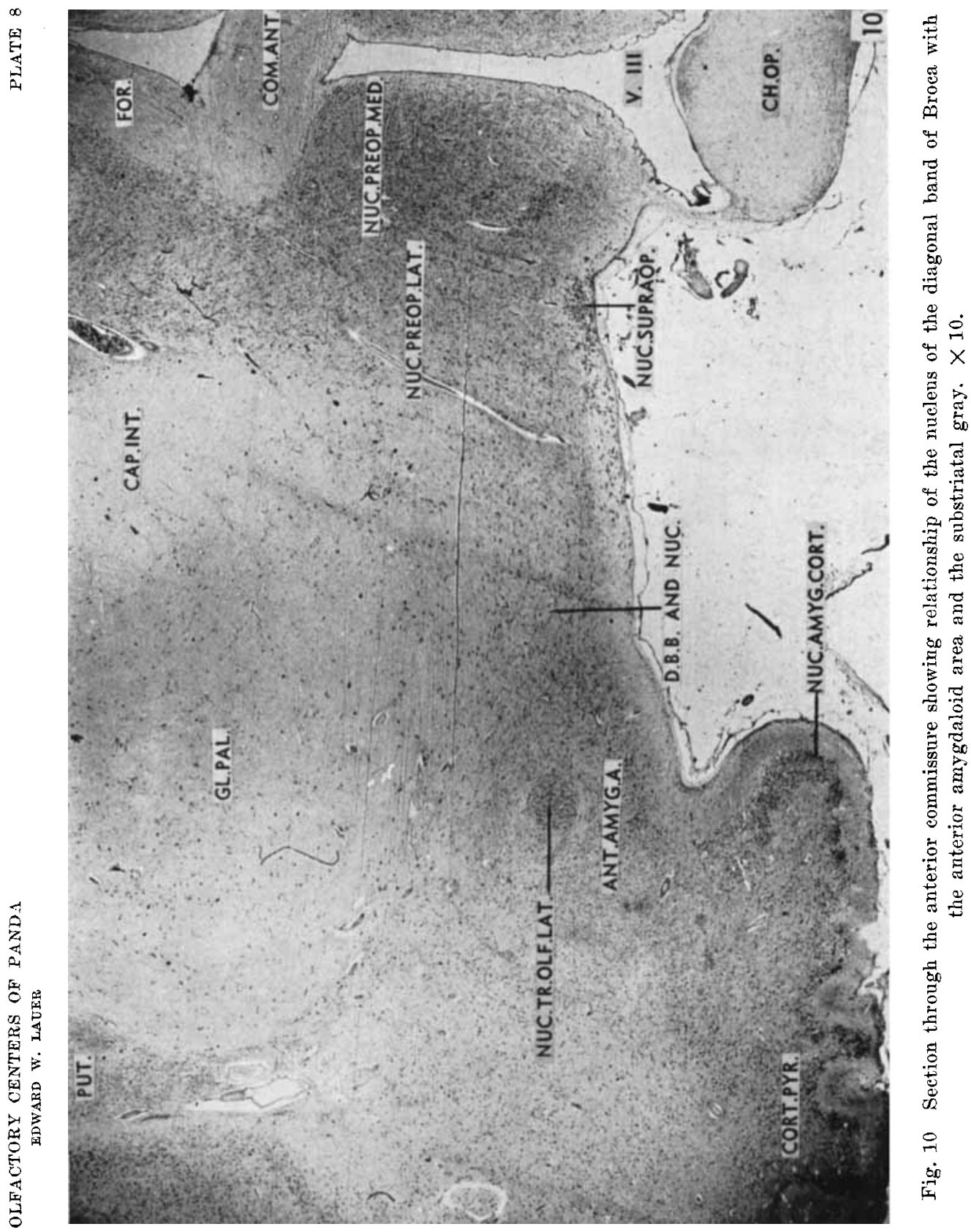




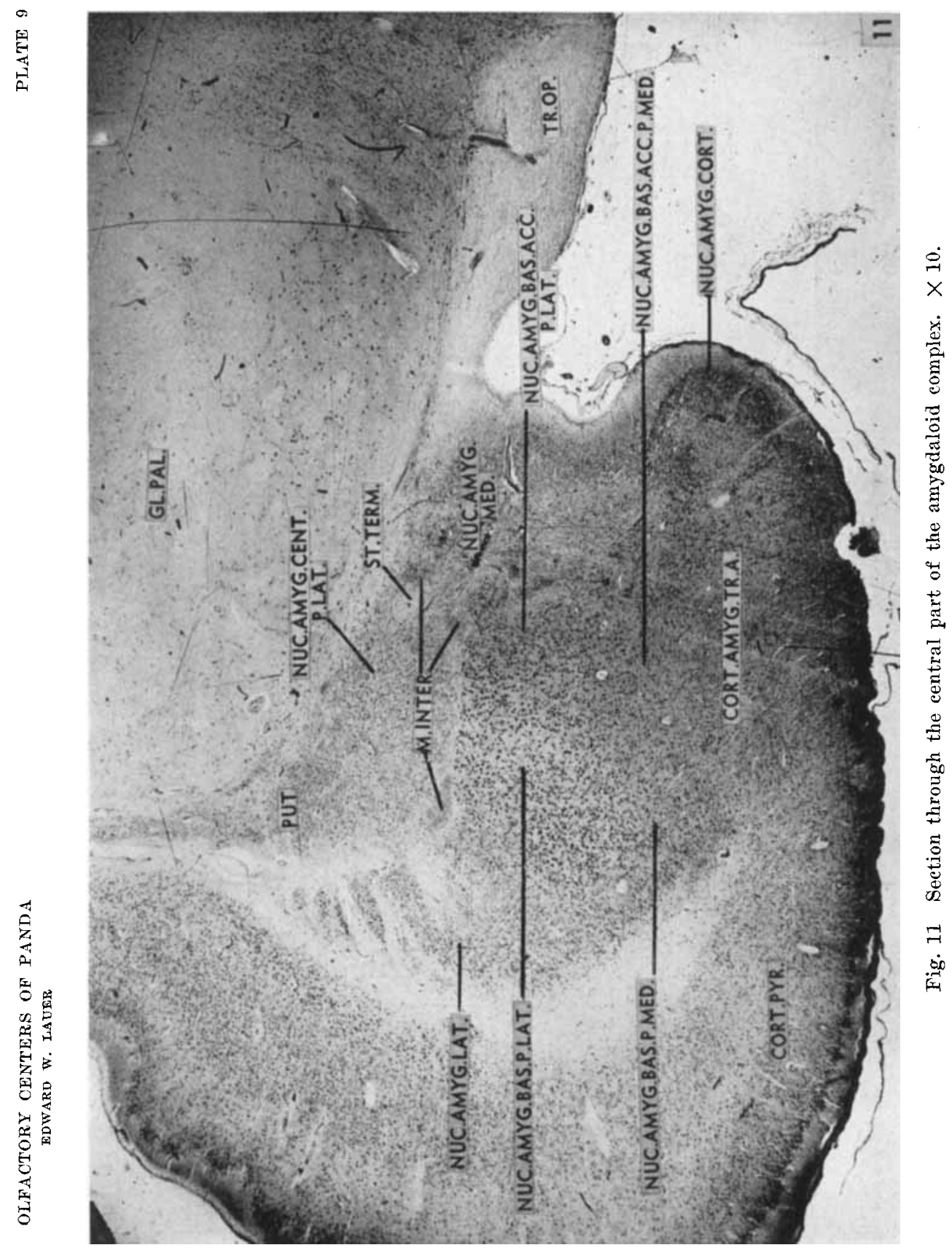




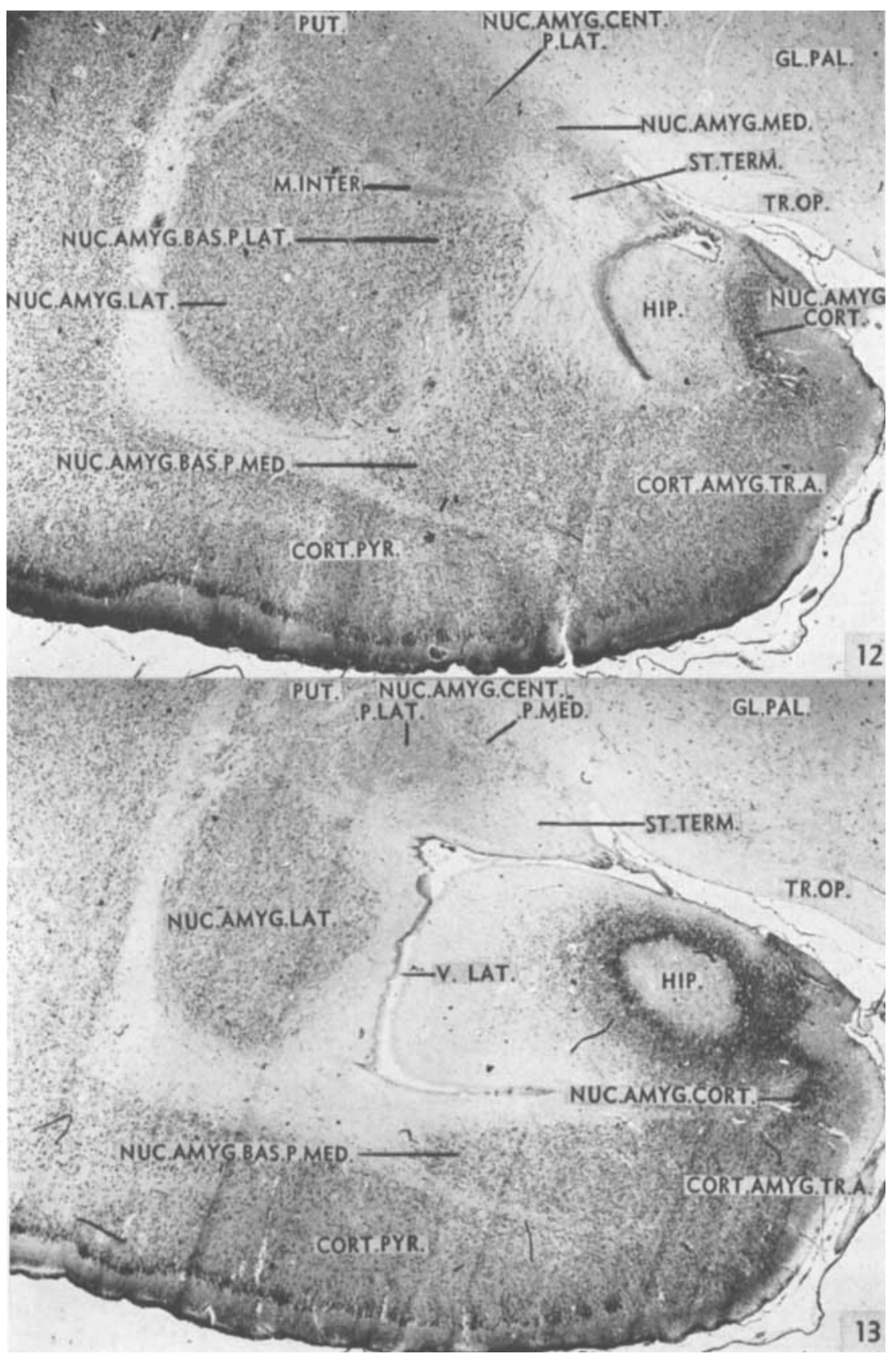

Figs. 12 and 13 Sections through the caudal end of the amygdala and the rostral tip of the hippocampus. $\times 10$. 